\title{
Effect of a Platelet Activating Factor Antagonist and Antithrombin III on Septicemia and Endotoxemia in Rats
}

\author{
Yuuichi Inoue, Shigeru Kohno, Takashige Miyazaki \\ and Keizou Yamaguchi
}

The Second Department of Internal Medicine, Nagasaki University School of Medicine, Nagasaki 852

\begin{abstract}
Inoue, Y., Кohno, S., Miyazaki, T. and Yamaguchi, K. Effect of a Platelet Activating Factor Antagonist and Antithrombin III on Septicemia and Endotoxemia in Rats. Tohoku J. Exp. Med., 1991, 163 (3), 175-185 — Disseminated intravascular coagulation (DIC) or renal damage associated with septicemia was induced in rats by ligating the cecum or by injecting endotoxin. In the septicemia model, the number of $E$. coli and Bacteroides spp in the blood increased concomitantly with an increase of endotoxin. In this model the development of hypercoagulability with mild fibrinolysis was observed. Histopathologic findings in the kidneys, including the formation of microthrombi in the glomeruli and the vacuolization and dilatation of renal tubular cells, suggest the development of mild DIC. In the endotoxin-induced DIC model, both remarkable state of hypercoagulability and fibrinolysis were observed with fibrin thrombi in glomeruli. The administration of the platelet-activating factor antagonist, CV-6209, or of human antithrombin III, ameliorated DIC significantly by limiting the increases in prothrombin time, activated partial thromboplastin time and fibrin degradation products. These agents significantly reduced the deposition of fibrin in the glomeruli and significantly prolonged the survival time of the endotoxin injected rats. These observations suggest that the PAF antagonist CV-6209 and ATIII merit clinical evaluation in the management of DIC caused by septisemia. antithrombin III (ATIII); endotoxin; CV-6209; DIC ; septicemia
\end{abstract}

Because of the development of chemotherapy, the treatment for infectious disease is not difficult in general. However, such complications as disseminated intravascular coagulation (DIC) or multiple organ failure (MOF) followed by septicemia is still refractory and shows a high mortality rate. MOF could be induced by septic shock or DIC with endotoxemia. The endotoxin seems to affect both the intrinsic and extrinsic pathways (Osterud and Bjorklid 1982 ; Rietschel et al. 1982 ; Colucci et al. 1983). The endotoxin activates factor XII directly (Morrison and Cochrane 1974) and stimulates the generation of the tissue factor from the monocytes and endothelial cells (Osterud and Bjorklid 1982 ; Colucci et

Received September 17, 1990 ; revision accepted for publication February 9, 1991.

Address for reprints: Shigeru Kohno, the Second Department of Internal Medicine, Nagasaki University School of Medicine, 7-1 Sakamoto-machi, Nagasaki 852, Japan. 
al 1983). To evaluate the role of septicemia or endotoxemia on DIC or renal damage as a part of MOF, experimental sepsis and endotoxemia models in rats were examined with respect to coagulation parameters and pathological changes in the kidneys. To evaluate the efficacy of antithrombin III (ATIII) and of a platelet-activating factor (PAF) antagonist, CV-6209, an endotoxin-induced model of DIC was induced in the rat and the effects of these agents were compared.

\section{Materials and Methods}

\section{Sepsis induced by cecal ligation}

Male Wistar rats weighing $300 \mathrm{~g}$ were anesthesized by phenobarbital $(0.25 \mathrm{mg} / \mathrm{kg}$; Abbott, IL, USA) and the abdominal wall was incised. The cecum was ligated and its wall was pierced with an 18-gauge needle to make 7 fine holes. The cecum was then pressed gently with the fingers to exude stool and thus to induce experimental peritonitis (Hirasawa et al. 1979). Twelve hours after cecal ligation, the rats were again anesthetized with phenobarbital $(0.25 \mathrm{mg} / \mathrm{kg})$ and the necrotic cecum was excised. The peritoneal cavity was washed twice with $20 \mathrm{ml}$ of sterile saline. Blood was drawn through the inferior vena cava for bacteriological evaluation and the measurement of endotoxin and coagulation factors at 6,12 and $24 \mathrm{hr}$ after ligation, respectively. There were $10 \mathrm{rats}$ in each group. The analysis of endotoxin was performed using a new endotoxin specific limulus test (endospecy test) (Tokyo Research Institute, Seikagaku Kogyo Co., Ltd., Tokyo) after treating with perchloric acid (PCA) as a method of human blood treatment.

$0.1 \mathrm{ml}$ of blood was diluted serially by sterile physiological saline. Lungs, kidneys and livers were extracted at 6 and $24 \mathrm{hr}$ after ligation under sterile condition, and homogenized with $2 \mathrm{ml}$ sterile physiological saline. These blood and organs were inoculated in the blood agar and the brain heart infusion agar for aerobic culture and in the BBE agar for anaerobic culture. The number of colonies of isolated bacteria was counted.

\section{Endotoxin-induced DIC}

Male Wister rats weighing $200 \mathrm{~g}$ were injected continuously with 50, 100 and $200 \mathrm{mg} /$ kg of E. coli endotoxin ( $E$. coli 055 : B5 LPS, phenol extracts, Sigma Chemical Co., St. Louis, MO, USA). The endotoxin diluted in $12.0 \mathrm{ml}$ of pyrogen-free physiological saline was infused into the femoral vein over $4 \mathrm{hr}$ by a compact syringe pump (Yoshikawa et al. 1982). Blood samples were drawn through the inferior vena cava for evaluation of coagulation factors. The kidneys were examined histologically following staining with hematoxylin-eosin and phosphotungstic acid-hematoxylin (PTAH) to observe any fibrin deposits in the glomeruli.

The effect of human antithrombin III (Hoechst Japan, Tokyo) and of the plateletactivating factor antagonist, CV-6209 (Takeda, Osaka) were evaluated on the rat DIC model induced by administering $100 \mathrm{mg}$ endotoxin/kg. ATIII and CV-6209 were dissolved separately in $1 \mathrm{ml}$ of pyrogen-free physiological saline. Just before the injection of endotoxin, either ATIII $(200 \mathrm{mg} / \mathrm{kg})$ or CV-6209 $(1 \mathrm{mg} / \mathrm{kg})$ were injected intravenously. Six rats were used in the ATIII group, 5 in the CV-6209 group and 5 in the untreated group. Changes in coagulation factors and in the survival time were observed and compared with those in the untreated (control) rats.

\section{Coagulation factors}

Fibrin degradation product (FDP), FDP-L (latex clumping method, semiquantitative method), FDP-E (E-domain, quantitative method), prothrombin time (PT) and activated partial thromboplastin time (APTT) were measured by the latex agglutination method (Allinton 1971), the latex photometric immunoassay (Dezelic and Dezelic 1970), and the 
method of Quick using simplastin and platelin (Quick et al. 1935), respectively. Platelets were counted by an automatic counter (Sysmex PL 110, Toua-iyoudensi, Kobe). Fibrinogen was measured by the rapid physiological coagulation method (Clauss 1957), alpha 2 plasmin inhibitor $\left(\alpha_{2}-\mathrm{PI}\right)$ by the amidolytic effect on the substrate S-2251 method (Friberger et al. 1978), ATIII by the chromogenic substrate method (Abildgaard et al. 1977), Cl-inhibitor by the turbidometric immunoassay (Gigli et al. 1968), fibronectin by the urease-GLDH method (Saba et al. 1981), factor XII by the Jaffe method (Lammle et al. 1983) and factor XIII by the dansylcadaverine incorporation and gel filtration method (Nishida et al. 1984).

\section{Statistical methods}

An unpaired $t$-test was used to compare the differences in coagulation factors between the treated and control groups. The generalized Wilcoxon's test was used to compare differences in survival times. The level of significance was $p<0.05$. All results were expressed as means \pm S.D.

\section{RESULT}

\section{Cecal ligation-induced sepsis}

The change in number of colonies vs. the level of endotoxin in the blood is shown in Fig. 1. E. coli and Bacteroides spp were isolated from the blood; the number of $E$. coli increased up to $5.0 \times 10^{4} \mathrm{cfu} / \mathrm{ml}$ and that of Bacteroides spp increased up to $3.2 \times 10^{4} \mathrm{cfu} / \mathrm{ml}$ with the increase of endotoxin $24 \mathrm{hr}$ after ligation. The number of $E$. coli in the kidneys, liver and lungs increased to $10^{6} \mathrm{cfu} / \mathrm{g} 24 \mathrm{hr}$ after cecal ligation. The number of Bacteroides $\operatorname{spp}$ increased to $10^{3} \mathrm{cfu} / \mathrm{g}$ in the lungs and kidneys and to $10^{2} \mathrm{cfu} / \mathrm{g}$ in the liver (Fig. 2). The platelet count and the levels of ATIII, $\alpha_{2}$-PI, factor XII and factor XIII all decreased (Table 1).

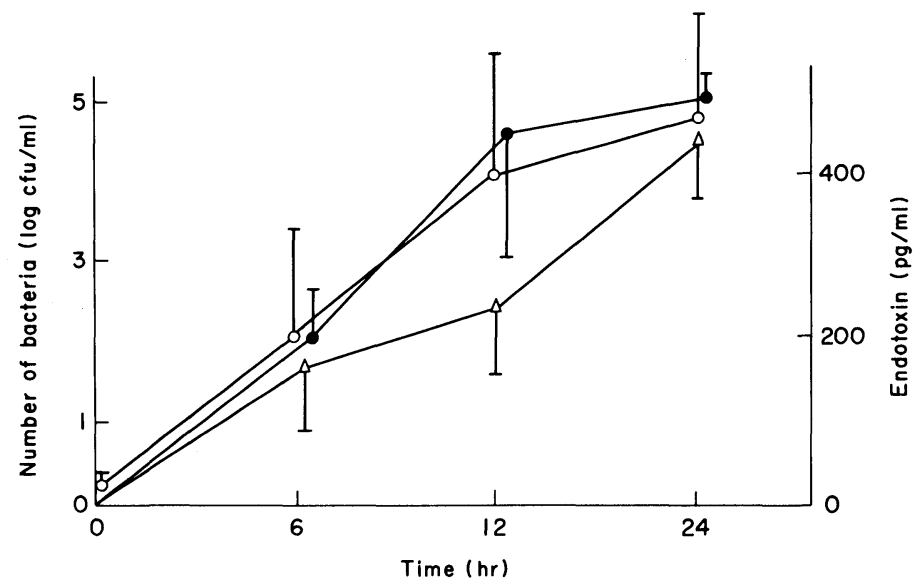

Fig. 1. Time course of bacterial colony counts and the level of endotoxin in the blood of rats with experimental sepsis induced by cecal ligation. At 24th following cecal ligation the number of $E$. coli was $5.0 \times 10^{4} \mathrm{cfu} / \mathrm{ml}$ and that of Bacteroides spp was $3.2 \times 10^{4} \mathrm{cfu} / \mathrm{ml}$. Endotoxin in the blood increased with time and was proportionate to the bacterial colony count. $\bigcirc$, endotoxin ; $\bullet$, E. coli; $\Delta$, Bacteroides spp. Results are means \pm S.D. $n=10$. 
TABLE 1. Change in coagulation factors after

\begin{tabular}{crrrcrr}
\hline $\begin{array}{c}\text { Time } \\
(\mathrm{hr})\end{array}$ & $\begin{array}{c}\text { Platelets } \\
\left(\times 10^{4}\right)\end{array}$ & $\begin{array}{c}\text { PT } \\
(\mathrm{sec})\end{array}$ & $\begin{array}{c}\text { APTT } \\
(\mathrm{sec})\end{array}$ & $\begin{array}{c}\text { Fibrinogen } \\
(\mathrm{mg} / 100 \mathrm{ml})\end{array}$ & $\begin{array}{c}\text { ATIII } \\
(\%)\end{array}$ & $\begin{array}{c}\text { FDP-L } \\
(\mathrm{ng} / \mathrm{ml})\end{array}$ \\
\hline 0 & 69.8 & 10.8 & 18.1 & 185.0 & 96.5 & 0.7 \\
& \pm 2.5 & \pm 0.9 & \pm 1.9 & \pm 22.0 & \pm 5.9 & \pm 0.7 \\
6 & 77.9 & 25.7 & 37.5 & 147.4 & 78.0 & 4.0 \\
& \pm 39.6 & \pm 1.8 & \pm 13.6 & \pm 20.0 & \pm 7.5 & \pm 3.7 \\
12 & 44.4 & 78.3 & 89.8 & 181.3 & 53.1 & 7.5 \\
& \pm 22.6 & \pm 52.7 & \pm 49.0 & \pm 42.4 & \pm 14.8 & \pm 2.5 \\
24 & 38.7 & 63.5 & 78.2 & 280.0 & 51.0 & 14.0 \\
& \pm 17.4 & \pm 61.3 & \pm 52.1 & \pm 113.0 & \pm 8.4 & \pm 16.3 \\
\hline
\end{tabular}

Results are expressed as mean \pm S.D.

PT, prothrombin time; APTT, activated partial thromboplastin time; ATIII, FDP-E, fibrin degradation product (E-domain) ; $\alpha_{2}$-PI, $\alpha_{2}$ plasmin inhibitor ; XII,
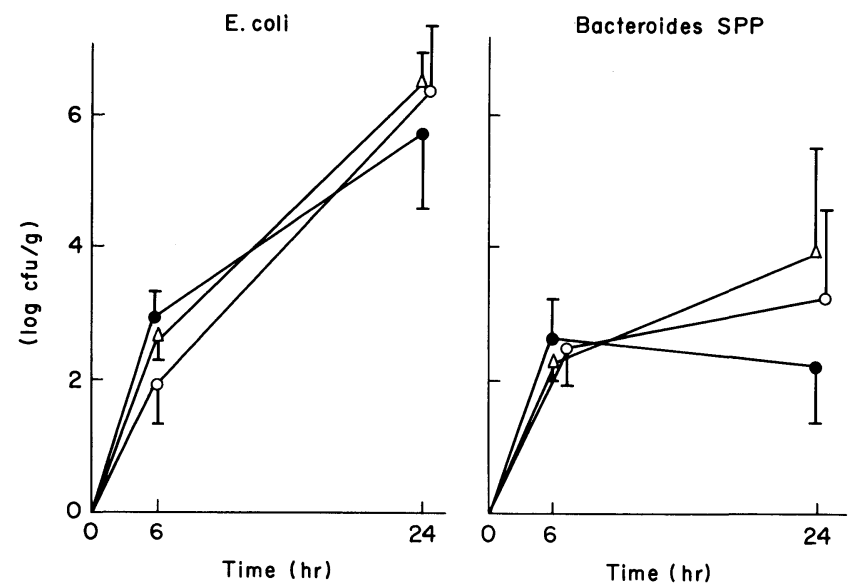

Fig. 2. Bacterial colony counts in the kidney $(\bigcirc)$ liver $(\bullet)$ and lung $(\Delta)$ of rats with experimental sepsis. The $E$. coli increased to about $10^{6} \mathrm{cfu} / \mathrm{g}$ in each organ $24 \mathrm{hr}$ after cecal ligation. The Bacteroides spp colony count reached about $10^{3} \mathrm{cfu} / \mathrm{g}$ in the lung and kidney and about $10^{2} \mathrm{cfu} / \mathrm{g}$ in the liver. Results are means \pm S.D.

PT and APTT were prolonged while the levels of fibrinogen, Cl-inhibitor, FDP-L and FDP-E all increased.

The deposition of thrombi in the glomeruli and the vacuolization or degeneration of cells in the proximal convoluted tubules was observed in all 10 rats subjected to this model of experimental sepsis $24 \mathrm{hr}$ after cecal ligation.

\section{Endotoxin-induced DIC}

An endotoxin-induced model of DIC was studied to observe the relationships among endotoxemia, DIC and multiple organ failure, especially renal damage. 
cecal ligation in rats (sepsis model)

\begin{tabular}{|c|c|c|c|c|c|}
\hline $\begin{array}{l}\text { FDP-E } \\
(\mu \mathrm{g} / \mathrm{ml})\end{array}$ & $\begin{array}{c}\alpha_{2}-\mathrm{PI} \\
(\%)\end{array}$ & $\begin{array}{l}\text { XII } \\
(\%)\end{array}$ & $\underset{(\%)}{\text { XIII }}$ & $\begin{array}{c}\text { Cl-Inhibitor } \\
(\%)\end{array}$ & $n$ \\
\hline $\begin{array}{r}1.6 \\
\pm 1.9\end{array}$ & $\begin{array}{l}137.0 \\
\pm 4.9\end{array}$ & $\begin{array}{r}224.0 \\
\pm 33.9\end{array}$ & $\begin{array}{r}109.7 \\
\pm 19.6\end{array}$ & $\begin{array}{r}31.0 \\
\pm 5.2\end{array}$ & 5 \\
\hline $\begin{array}{r}194.8 \\
\pm 93.5\end{array}$ & $\begin{array}{l}123.0 \\
\pm 6.4\end{array}$ & $\begin{array}{r}89.5 \\
\pm 39.8\end{array}$ & $\begin{array}{r}54.5 \\
\pm 32.1\end{array}$ & $\begin{array}{r}32.7 \\
\pm 5.2\end{array}$ & 10 \\
\hline $\begin{array}{r}152.2 \\
\pm 73.2\end{array}$ & $\begin{array}{r}106.6 \\
\pm 21.9\end{array}$ & $\begin{array}{r}58.0 \\
\pm 20.4\end{array}$ & $\begin{array}{r}36.2 \\
\pm 20.4\end{array}$ & $\begin{array}{r}34.8 \\
\pm 6.2\end{array}$ & 10 \\
\hline $\begin{array}{r}193.0 \\
\pm 332.0\end{array}$ & $\begin{array}{r}106.7 \\
\pm 22.2\end{array}$ & $\begin{array}{r}72.5 \\
\pm 36.5\end{array}$ & $\begin{array}{r}26.7 \\
\pm 12.6\end{array}$ & $\begin{array}{r}47.3 \\
\pm 18.8\end{array}$ & 10 \\
\hline
\end{tabular}

antithrombin III ; FDP-L, fibrin degradation product (latex clumping method); factor XII ; XIII, factor XIII ; n,number of animals.

The highest rate of glomerular fibrin deposition (\%GFD) was observed $4 \mathrm{hr}$ after the injection of endotoxin $(100 \mathrm{mg} / \mathrm{kg})$ in the animals and increased gradually over time (Table 2). Histopathologic examination showed fibrin thrombi in the renal glomeruli, with vacuolization and granular changes in the proximal convoluted tubules (Fig. 3).

The coagulation factors such as factor XII, factor XIII, $\alpha_{2}-\mathrm{PI}$, fibronectin and Cl-inhibitor were decreased together with a remarkable reduction of platelets and ATIII, PT and APTT were prolonged to a greater extent than in the sepsis model. FDP-E increased more rapidly and reached higher concentrations than in the sepsis model (Table 3). Both fibrinogen and Cl-inhibitor decreased in the endotoxin model whereas they increased in the sepsis model.

The effect of ATIII on the DIC induced by endotoxin was evaluated (Table 4). The levels of PT, FDP-L and FDP-E improved significantly in the treated as compared to the control (untreated) groups $(p<0.01)$. The levels of APTT, $\alpha_{2}$-PI, factor XII and fibronectin also improved significantly $(p<0.05)$. In the ATIII-treated rats, the amount of fibrin deposited in the glomeruli was significantly less than that in the controls at $3 \mathrm{hr}$ after endotoxin injection, evevn though it increased with time (Fig. 4).

TABLE 2. Change in fibrin deposits in endotoxin-infused rats (DIC model)

\begin{tabular}{ccc}
\hline Dose of endotoxin & \multicolumn{2}{c}{ GFD (\%) } \\
\hline 0 & 0 & $(n=5)$ \\
50 & $56.0 \pm 15.4$ & $(n=6)$ \\
100 & $65.9 \pm 17.8$ & $(n=7)$ \\
200 & $30.5 \pm 20.8$ & $(n=5)$ \\
\hline
\end{tabular}

\begin{tabular}{crr}
\hline Time (hr) & \multicolumn{2}{c}{ GFD (\%) } \\
\hline 1 & $0.25 \pm 0.6$ & $(n=8)$ \\
2 & $5.8 \pm 9.6$ & $(n=5)$ \\
3 & $42.8 \pm 14.3$ & $(n=6)$ \\
4 & $65.9 \pm 17.8$ & $(n=7)$ \\
\hline
\end{tabular}

Results are expressed as mean \pm s.D. $100 \mathrm{mg} / \mathrm{kg}$ endotoxin was injected. 
TABLE 3. Coagulation factors in

\begin{tabular}{crrrcrr}
\hline $\begin{array}{c}\text { Time } \\
(\mathrm{hr})\end{array}$ & $\begin{array}{c}\text { Platelets } \\
\left(\times 10^{4}\right)\end{array}$ & $\begin{array}{c}\text { PT } \\
(\mathrm{sec})\end{array}$ & $\begin{array}{c}\text { APTT } \\
(\mathrm{sec})\end{array}$ & $\begin{array}{c}\text { Fibrinogen } \\
(\mathrm{mg} / 100 \mathrm{ml})\end{array}$ & $\begin{array}{c}\text { ATIII } \\
(\%)\end{array}$ & $\begin{array}{r}\text { FDP-L } \\
(\mu \mathrm{g} / \mathrm{ml})\end{array}$ \\
\hline \multirow{2}{*}{0} & 69.8 & 10.8 & 18.1 & 185.0 & 96.5 & 0.7 \\
& \pm 2.5 & \pm 0.9 & \pm 1.9 & \pm 22.0 & \pm 5.9 & \pm 0.7 \\
1 & 67.1 & 11.1 & 23.3 & 141.2 & 82.3 & 0.4 \\
& \pm 33.7 & \pm 1.0 & \pm 5.3 & \pm 10.9 & \pm 1.3 & \pm 0.4 \\
2 & 43.6 & 12.8 & 55.6 & 134.5 & 88.0 & 6.6 \\
& \pm 15.8 & \pm 1.7 & \pm 32.4 & \pm 28.5 & \pm 1.0 & \pm 7.6 \\
3 & 24.0 & 119.4 & 150.0 & 35.3 & 55.5 & 80.0 \\
& \pm 17.1 & \pm 53.1 & \pm 0 & \pm 0.4 & \pm 43.0 & \pm 49.0 \\
4 & 18.5 & 150.0 & 150.0 & 31.8 & 45.5 & 92.0 \\
& \pm 9.4 & \pm 0 & \pm 0 & \pm 5.6 & \pm 3.9 & \pm 58.8 \\
\hline
\end{tabular}

Results are expressed as mean土s.D.

The influence of PAF antagonist, CV-6209, in the rat DIC model was also evaluated (Table 4). The FDP-L improved significantly $(p<0.01)$ and PT, APTT, $\alpha_{2}$-PI, FDP-E and fibronectin also improved significantly $(p<0.05)$. Furthermore, the survival time of the CV-6209-treated rats was significantly longer than that of the controls $(p<0.05$, Fig. 5$)$.

\section{Discussion}

Endotoxin consists of lipopolysaccharides (LPS) present in the outer membrane of gram-negative-rods. We evaluated the role of endotoxin in producing multiple organ failure as observed in DIC, and evaluated its effect on the kidney in an experimental sepsis model and in an endotoxin-induced model of DIC.

In the sepsis model, the number of $E$. coli and Bacteroides spp increased with the increase of endotoxin $24 \mathrm{hr}$ after ligation and the increase rate of the number of bacteria was parallel to that of endotoxin. Both of $E$. coli and Bacteroides spp have lipopolysaccharides, althogh endotoxic potency of Bacteroides spp is weak (Simon et al. 1985). A remarkable change in platelet counts, ATIII, PT and APTT and a mild change in $\alpha_{2}$-PI and FDP suggested the development of hypercoagulability with mild fibrinolysis. This could be due to a slow increase of endotoxin in the blood and, or the clearance of endotoxin by Kupffer's cells. The increase of fibrinogen and Cl-inhibitor suggest that their production in the liver have been greater than their utilization. Histopathologic finding in the kidneys, including the formation of microthrombi in the glomeruli and the vacuolization and dilatation of renal tubular cells, suggest the development of mild DIC.

In the endotoxin-induced model of DIC, the increase in coagulation factors suggested a remarkable state of hypercoagulability with fibrinolysis. Fibrin thrombi found in the glomeruli and the associated changes were attributed to the large dose of endotoxin injected. 
rats following endotoxin injection

\begin{tabular}{rcccrrr}
\hline $\begin{array}{c}\text { FDP-E } \\
(\mathrm{ng} / \mathrm{ml})\end{array}$ & $\begin{array}{c}\alpha_{2} \text {-PI } \\
(\%)\end{array}$ & $\begin{array}{c}\text { Fibronectin } \\
(\mu \mathrm{g} / \mathrm{ml})\end{array}$ & $\begin{array}{c}\text { XII } \\
(\%)\end{array}$ & $\begin{array}{c}\text { XIII } \\
(\%)\end{array}$ & $\begin{array}{c}\text { Cl-Inhibitor } \\
(\%)\end{array}$ & $n$ \\
\hline 1.6 & 136.8 & 50.3 & 224.5 & 109.7 & 31.0 & 5 \\
\pm 1.9 & \pm 4.9 & \pm 6.2 & \pm 33.9 & \pm 19.6 & \pm 5.2 & \\
18.7 & 106.6 & 42.4 & 197.6 & 70.0 & 26.8 & 5 \\
\pm 19.9 & \pm 11.9 & \pm 2.3 & \pm 71.0 & \pm 43.3 & \pm 2.6 & \\
363.3 & 109.0 & 41.2 & 204.4 & 38.8 & 25.0 & 5 \\
\pm 326.9 & \pm 11.9 & \pm 2.4 & \pm 63.3 & \pm 29.9 & \pm 0 & \\
2684.5 & 93.3 & 41.5 & 143.8 & 25.5 & 26.5 & 5 \\
\pm 324.5 & \pm 14.5 & \pm 2.1 & \pm 18.9 & \pm 6.6 & \pm 2.6 & \\
2533.4 & 77.7 & 42.0 & 133.0 & 30.3 & 25.0 & 7 \\
\pm 536.0 & \pm 11.3 & \pm 1.4 & \pm 49.8 & \pm 11.5 & \pm 0 & \\
\hline
\end{tabular}

TABLE 4. Effect of ATIII or CV-6209 on coagulation factors in endotoxin-injected rats (DIC model)

\begin{tabular}{llccc}
\hline & & $\begin{array}{c}\text { No therapy } \\
(n=7)\end{array}$ & $\begin{array}{c}\text { ATIII } \\
(n=6)\end{array}$ & $\begin{array}{c}\text { CV-6209 } \\
(n=5)\end{array}$ \\
\hline Platelets & $\left(\times 10^{4}\right)$ & $18.5 \pm 9.4$ & $16.1 \pm 3.7$ & $14.8 \pm 6.1$ \\
PT & $(\mathrm{sec})$ & $150.0 \pm 0$ & $40.9 \pm 48.8^{* *}$ & $54.8 \pm 56.1^{*}$ \\
APTT & $(\mathrm{sec})$ & $150.0 \pm 0$ & $97.0 \pm 53.1^{*}$ & $89.8 \pm 60.1^{*}$ \\
Fibrinogen & $(\mathrm{mg} / 100 \mathrm{ml})$ & $31.8 \pm 5.6$ & $40.3 \pm 14.2$ & $51.0 \pm 24.6$ \\
ATIII & $(\%)$ & $45.5 \pm 13.9$ & $113.2 \pm 11.1^{* *}$ & $57.0 \pm 8.9$ \\
FDP-L & $(\mu \mathrm{g} / \mathrm{ml})$ & $92.0 \pm 58.8$ & $15.8 \pm 6.1^{* *}$ & $25.0 \pm 15.0^{* *}$ \\
FDP-E & $(\mathrm{ng} / \mathrm{ml})$ & $2533.4 \pm 536.0$ & $1161.0 \pm 370.0^{* *}$ & $1332.8 \pm 646.6^{*}$ \\
$\alpha_{2}$-PI & $(\%)$ & $77.7 \pm 11.3$ & $89.2 \pm 8.2^{*}$ & $97.0 \pm 8.5^{*}$ \\
Fibronectin & $(\mu \mathrm{g} / \mathrm{ml})$ & $42.0 \pm 1.4$ & $46.2 \pm 3.5^{*}$ & $47.3 \pm 4.0^{*}$ \\
Factor XII & $(\%)$ & $133.0 \pm 49.8$ & $216.7 \pm 42.3^{*}$ & $130.5 \pm 30.9$ \\
Factor XIII & $(\%)$ & $30.3 \pm 11.5$ & $32.5 \pm 15.7$ & $28.5 \pm 13.2$ \\
C ${ }_{1}$-Inhibitor & $(\%)$ & $25.0 \pm 0$ & $25.3 \pm 0.7$ & $27.0 \pm 3.5$ \\
\hline
\end{tabular}

Results are expressed as mean \pm S.D

${ }^{*} p<0.05 ;{ }^{* *} p<0.01$ vs. corresponding values in no therapy.

The administration of ATIII significantly improved the change of coagulation factors but not of platelet counts. The platelet counts were not influenced by ATIII (Prager et al. 1979 ; Doebber et al. 1985 ; Mammer et al. 1985). ATIII inhibits the activity of kallikrein and prevents the decrease in the plasma level of factor XII observed during endotoxemia (Triantaphillopoulos 1984). The administration of ATIII prevented the decrease of factor XII to a significant extent in this model of DIC, while the PAF-antagonist CV-6209 had no effect on this coagulation factor. The latter was the only observed difference between the effects of ATIII and CV-6209. 


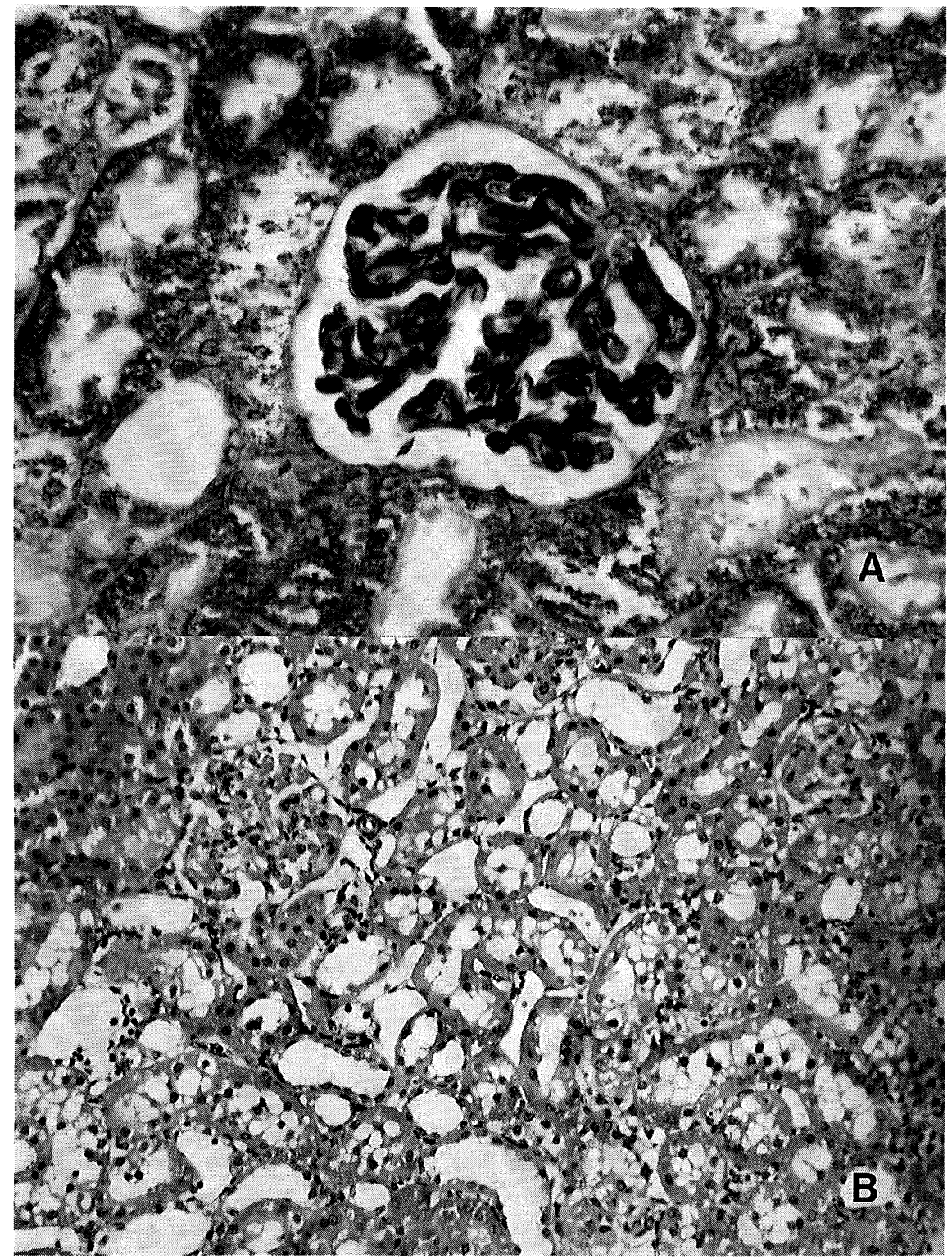

Fig. 3. Pathology of the rat kidney on DIC. A. Fibrin thrombi in the renal glomeruli of rat with DIC. (PTAH staining, $\times 200$ ) B. Vacuolization and granular changes were observed in the proximal convoluted tubules. (HE staining, $\times 100)$ 


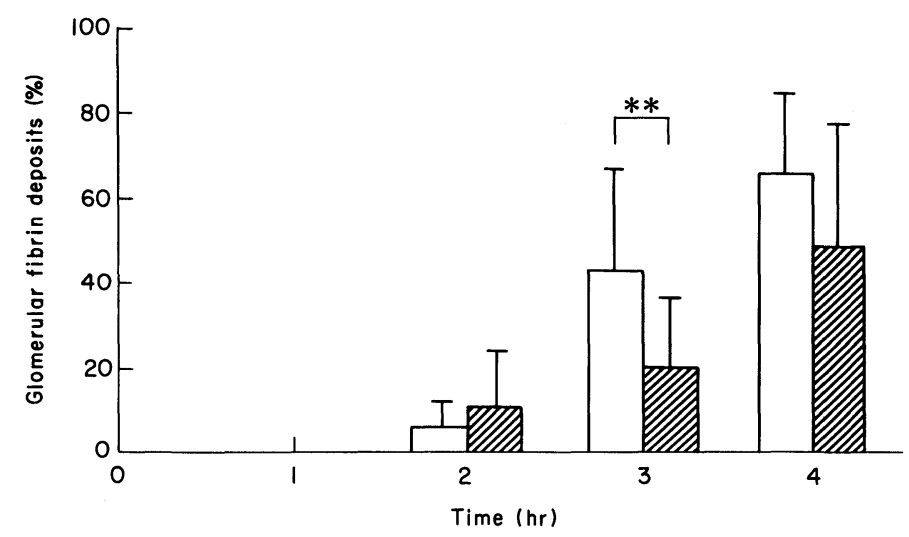

Fig. 4. The effect of ATIII on the fibrin deposition in the renal glomeruli. The deposition rate of fibrin in the glomeruli was significantly less in the ATIIItreated group with DIC than in the untreated controls. $\square$ controls; $\square m$ ATIII $(200 \mathrm{mg} / \mathrm{kg})$. Results are means \pm s.D. ${ }^{* *} p<0.01$.

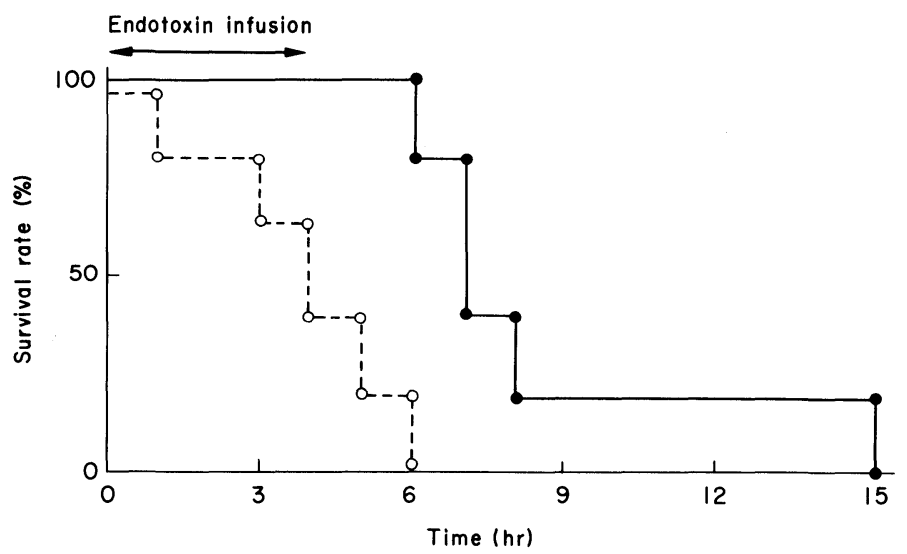

Fig. 5. The effect of CV-6209 on survival curve after endotoxin infusion. Just before the injection of endotoxin, CV-6209 (1 mg/kg) were injected intravenously. The endotoxin $(100 \mathrm{mg} / \mathrm{kg})$ was injected continuously over 4 hr. The survival time of the CV-6209-treated rats with endotoxin-induced DIC was significantly longer than that of the controls $(p<0.05)$. $\bigcirc$ vehicle ; - CV-6209 $10 \mathrm{mg} / \mathrm{kg}$.

Platelet-activating factor (PAF) is a new lipid chemical mediator that exhibits various biological actions such as activation of platelets and leukocytes, a hypotensive effect, a negative inotropic cardiac effects, bronchoconstriction and an increase in vascular permeability (Benveniste and Vargaftig 1983; Hanahan 1986). In addition, PAF may play an important role in the pathogenesis of endotoxin shock and DIC. It has been reported that PAF induced DIC-like 
change like endotoxin, and a specific PAF-antagonist, CV-3988 improved DIC parameters that had been alterd by endotoxin or PAF (Imura et al. 1986). Important proof for the mediator role of PAF in endotoxin-induced DIC or schock would include demonstration of PAF production in vivo in response to endotoxin and inhibition of an endotoxin-induced response by a specific PAF-receptor antagonist. The injection of endotoxin has increased the level of blood PAF and endotoxin-induced hypotension and/or death have been improved by PAF antagonist (Doebber et al. 1985). PAF is produced in large amounts in the lungs following the intravenous injection of endotoxin (Chang et al. 1987). The biological action of endotoxin are very complicated, and various actions such as activation of Hageman's factor and proteolytic enzyme and the release of tissue factor and PAF might contribute to the pathogenesis of DIC induced by endotoxin. But the precise mechanism of the action of PAF on the in vivo blood coagulation system remains to be clarified. We studied the effect of the PAFantagonist CV-6209 on endotoxin-induced DIC model. Hypercoagulability and fibrinolysis were both improved by this agent. It also significantly improved the survival time of rats adminstered endotoxin.

From these observations, ATIII and the PAF-antagonist CV-6209 are thought to be useful in treating endotoxin-induced DIC in rats.

\section{References}

1) Abildgaard, U., Lie, M. \& Odegard, O.R. (1977) Antithrombin (heparin cofactor) assay with "new" chromogenic substances (S-2238 and chromozym TH). Thromb. Res., 11, 549-553.

2) Allinton, M.J. (1971) Detection of fibrin(ogen) degradation products by a latex clumping method. Scand. J. Haematol., 13, 115-119.

3) Benveniste, J. \& Vargaftig, B.B. (1983) Platelet-activating factor: An ether lipid with biological activity. In: Ether Lipids : Biochemical and Biomedical Aspects, Academic Press, New York, pp. 355-376.

4) Chang, S., Fedderson, C.O., Henson, P.M. \& Voelkel, N.F. (1987) Platelet activating factor mediates hemodinamic changes in lung injuly in endotoxin-treated rats. $J$. Clin. Invest., 79, 1498-1509.

5) Clauss, A. (1957) Gerinnung Sphysiologische Schneiomethode Zur Bestimmung des Fibrinogens. Acta Haemost., 17, 237-246.

6) Colucci, M., Balconi, G., Lorenzet, R., Pietra, A., Donati, M.B. \& Semeraro, N. (1983) Evidence that cultured human endothelial cells(EC) generate tissue factor in responce to endotoxin. Thromb. Haemost., 50, 253. (Abstract)

7) Dezelic, N. \& Dezelic, G.J. (1970) A photometric method for the determination of serum titers by latex particle agglutination. Croatica Chemica Acta, 42, 457-466.

8) Doebber, T.W., Wu, M.S., Robbins, J.C., Choy, B.M., Chang, M.N. \& Shen, T.Y. (1985) Platelet activating factor (PAF) involvement in endotoxin induced hypotention in rats. Studies with RA-receptor antagonist Kadsurenone. Biochem. Biophys. Res. Commun., 127, 799-808.

9) Friberger, P., Knos, M., Gutavsson, S., Aurell, L. \& Claeson, G. (1978) Methods for determination of plasmin, antiplasmin and plasminogen by means of substrate S-2251. Haemostasis, 7, 138-145.

10) Gigli, I., Ruddy, S. \& Austin, K.F. (1968) The stoichiometric measurement of the 
serum inhibitor of the first component of complement by the inhibition of immune hemolysis. J. Immunol., 100, 1154-1164.

11) Hanahan, D.J. (1986) Platelet activating factor: A biologically active phosphoglycerid. Annu. Rev. Biochem., 55, 483-509.

12) Hirasawa, H., Tabata, Y., Ohkawa, M., Soeda, K., Odaka, M. \& Satoh, H. (1979) The treatment of sepsis with intravenous administration of $\mathrm{ATP}-\mathrm{MgCl}_{2}$ and glucose. $J$. Jpn. Surg. Soc., 80, 164-172.

13) Imura, Y., Terashita, Z. \& Nishikawa, K. (1986) Possible role of platelet activating factor (PAF) in disseminated intravascular coagulation(DIC), evidenced by use of a PAF antagonist, CV3988. Life Sci., 39, 111-117.

14) Lammle, B., Tran, T.H. \& Duckert, F. (1983) Assay of factor XII clotting activity in heparinized plasma. Am. J. Clin. Pathol., 80, 474-477.

15) Mammer, E.F., Miyakawa, T., Phillips, T.F., Assarian, G.S., Brown, J.M. \& Morano, G. (1985) Human antithrombin concentrates and experimental disseminated intravascular coagulation. Semin. Thromb. Hemost., 11, 373-383.

16) Morrison, D.C. \& Cochrane, C.G. (1974) Direct evidence for Hageman factor (factor XII) activation by bacterial lipopolysaccharides (endotoxins). J. Exp. Med., 140, 797-811.

17) Nishida, Y., Ikematsu, S., Fukutake, K., Fujimaki, M. \& Kakishita, E. (1984) A new rapid and simple assay for factor XIII activity using dansylocadaverine incorporation and gel filtration. Thrombo. Res., 36, 123-131.

18) Osterud, B. \& Bjorklid, E. (1982) Human factor VII associated with endotoxin stimulated monocytes in whole blood. Boichem. Biophys. Res. Commun., 108, 620626.

19) Prager, R.L., Dunn, E.L., Kirsh, M.M. \& Renner, J.A. (1979) Endotoxin induced intravascular coagulation(DIC) and its therapy. Adv. Shock. Res., 2, 277-287.

20) Quick, A.J., Stanly, B.M. \& Bancroft, F.W. (1935) A study of the coagulation defect in hemophilia and in jaundice. Am. J. Med. Sci., 190, 501-511.

21) Rietschel, E.T., Shade, U., Jensen, M., Woiienweber, H.W., Luderitz, O. \& Greisman, S.G. (1982) Bacterial endotoxins: Chemical structure, biological activity and role in septicemia. Scand. J. Infect. Dis., 31, 8-21.

22) Saba, T.M., Albert, W.H., Blumenstock, F.A., Evanega, G., Staehler, F. \& Cho, E. (1981) Evaluation of a rapid immunoturbidimetric assay for opsonic fibronectin in surgical and trauma patients. J. Lab. Clin. Med., 98, 482-491.

23) Simon, L.G., Gelfand, A.J., Connolly, A.R., O'donnel, F.T. \& Gorbach, L.S. (1985) Experimental bacteroides fragilis bacteremia in a primate model: Evidence that Bacteroides fragilis does not promote the septic shock syndrome. J. Trauma, 25, $1156-1162$.

24) Triantaphillopoulos, D.C. (1984) Effect of human antithrombin III on mortality and blood coagulation induced in rabbits by endotoxin. Tromb. Haemost., 51, 232235.

25) Yoshikawa, T., Furukawa, Y., Murakami, M., Takemura, S. \& Kondou, M. (1982) Protection of endotoxin-induced disseminated intravascular coagulation in rats by gabexate mesilate. Acta Haematol. Jpn., 45, 633-640. 